Research

\title{
Limited copy number - high resolution melting (LCN-HRM) enables the detection and identification by sequencing of low level mutations in cancer biopsies Hongdo Do ${ }^{1,2}$ and Alexander Dobrovic*1,2
}

\author{
Address: ${ }^{1}$ Department of Pathology, University of Melbourne, Parkville, Victoria, 3010, Australia and ${ }^{2}$ Molecular Pathology Research and \\ Development Laboratory, Department of Pathology, Peter MacCallum Cancer Centre, Locked Bag 1, A'Beckett St, Melbourne, Victoria 8006, \\ Australia \\ Email: Hongdo Do - hongdo.do@petermac.org; Alexander Dobrovic* - alex.dobrovic@petermac.org \\ * Corresponding author
}

This article is available from: http://www.molecular-cancer.com/content/8/1/82

(C) 2009 Do and Dobrovic; licensee BioMed Central Ltd.

This is an Open Access article distributed under the terms of the Creative Commons Attribution License (http://creativecommons.org/licenses/by/2.0), which permits unrestricted use, distribution, and reproduction in any medium, provided the original work is properly cited.

\begin{abstract}
Background: Mutation detection in clinical tumour samples is challenging when the proportion of tumour cells, and thus mutant alleles, is low. The limited sensitivity of conventional sequencing necessitates the adoption of more sensitive approaches. High resolution melting (HRM) is more sensitive than sequencing but identification of the mutation is desirable, particularly when it is important to discriminate false positives due to PCR errors or template degradation from true mutations.

We thus developed limited copy number - high resolution melting (LCN-HRM) which applies limiting dilution to HRM. Multiple replicate reactions with a limited number of target sequences per reaction allow low level mutations to be detected. The dilutions used (based on $\mathrm{Ct}$ values) are chosen such that mutations, if present, can be detected by the direct sequencing of amplicons with aberrant melting patterns.

Results: Using cell lines heterozygous for mutations, we found that the mutations were not readily detected when they comprised $10 \%$ of total alleles ( $20 \%$ tumour cells) by sequencing, whereas they were readily detectable at $5 \%$ total alleles by standard HRM. LCN-HRM allowed these mutations to be identified by direct sequencing of those positive reactions.

LCN-HRM was then used to review formalin-fixed paraffin-embedded (FFPE) clinical samples showing discordant findings between sequencing and HRM for KRAS exon 2 and EGFR exons 19 and 21 . Both true mutations present at low levels and sequence changes due to artefacts were detected by LCN-HRM. The use of high fidelity polymerases showed that the majority of the artefacts were derived from the damaged template rather than replication errors during amplification.
\end{abstract}

Conclusion: LCN-HRM bridges the sensitivity gap between HRM and sequencing and is effective in distinguishing between artefacts and true mutations. 


\section{Background}

The recent demonstrations of the clinical benefits of molecularly targeted therapies $[1,2]$ have greatly increased the demand for cost-effective and reliable methods of mutation detection in individual tumour samples. However, clinical tumour samples are typically heterogeneous, containing a mixture of cancer cells and various normal cell types. The proportion of cancer cells can be quite low and often limited amounts of material are available for analysis. The cancer cells may also show clonal heterogeneity, and thus a particular genetic change may not be present in all of the tumour cells [3]. All of these factors present challenges for mutation detection in clinical samples.

Dideoxynucleotide sequencing is often considered the gold standard for detection of genetic changes as it allows these changes to be directly characterised. However, to be reliably detected, changes are required to be present at a proportion of at least $10-20 \%$ at the allelic level [4]. Thus, lower levels of mutations, due to high contamination with normal cells or tumour heterogeneity, can not be detected by sequencing when the mutations are present below the sensitivity of sequencing.

Various PCR-based techniques for detecting sequence variation have been reported, demonstrating both advantages and disadvantages in terms of sensitivity, simplicity, cost-efficiency and robustness. This article will focus on the detection of EGFR and KRAS mutations, although the principles can be extended to mutations in any gene. Reported techniques available for detection of mutations in these genes include; dideoxynucleotide sequencing, single strand conformation analysis [5], TaqMan PCR [6], amplification refractory mutation system monitored by Scorpion probes [7], denaturing high pressure liquid chromatography [8], pyrosequencing [9], massively parallel sequencing $[10,11]$, cold-PCR [12], mutant-enriched PCR [13] and high resolution melting [14,15].

High resolution melting (HRM) is an in-tube scanning methodology that detects sequence variation by monitoring the melting behaviour of PCR amplicons using DNA intercalating fluorescent dyes. HRM has been used for a variety of genetic and epigenetic studies [14-18]. It has been demonstrated to be more sensitive than dideoxynucleotide sequencing for the detection of somatic mutations [19]. In our previous study, KRAS mutations were able to be detected at levels as low as 5\% by HRM [14].

Like other scanning methods, HRM results often need to be confirmed and characterised by a sequencing methodology. Dideoxynucleotide sequencing is the most commonly used methodology. Discordant results between sequencing and HRM may be anticipated if the mutant alleles are present at 5 to $20 \%$ due to the different sensitivity of the two methods.

In this study, we report a new method, LCN-HRM, for detection and subsequent identification by sequencing of low levels of sequence variation, particularly those that are only detectable by HRM. The basic principle of this methodology is that low level mutant alleles which cannot be detected in the presence of large amounts of normal alleles are present at higher proportions when the sample is diluted at low copy numbers in multiple aliquots (limiting dilution) [20,21]. The range of copy numbers are chosen so that aliquots containing mutations can be detected with HRM and the mutations can then be characterised by direct sequencing of the aberrant amplicons.

\section{Methods \\ Samples and DNA extraction}

This study was covered by an approval from the Peter MacCallum Cancer Centre Ethics Committee (project number 03/90). Two cancer cell lines, HCT116 and NCIH1650, were used. HCT116 contains a KRAS exon 2 missense mutation whereas NCI-H1650 harbours a EGFR exon 19 deletion mutation. Peripheral blood from four normal individuals was used as a source of DNA for the quantitative estimation of target copy number and as normal DNA for the cell line dilution experiments. Genomic DNA was extracted from the cell lines and peripheral blood using the QIAamp DNA blood kit (Qiagen, Hilden, Germany) according to the manufacturer's instructions. DNA was quantified with a NanoDrop ND-1000 Fluorospectrometer (NanoDrop, Wilmington, DE). Four formalin-fixed paraffin-embedded (FFPE) DNA samples from non-small cell lung cancer (NSCLC) patients were included to investigate the cause of previously reported discrepancies between HRM and sequencing results [15].

\section{$P C R$ and HRM conditions}

Real time PCR amplification and HRM were performed on the Rotor-Gene Q (Qiagen, Hilden, Germany). The HRM primers for KRAS exon 2 [14] and EGFR exon 19 [15] generated $189 \mathrm{bp}$ and $250 \mathrm{bp}$ products respectively. The conditions for KRAS exon 2 were as follows. The reaction mixture (20 $\mu \mathrm{l}$ final volume) contained the template, $1 \times$ PCR buffer, $2.5 \mathrm{mM} \mathrm{MgCl}_{2}, 200 \mathrm{nM}$ each primer, 200 $\mu \mathrm{M}$ dNTPs, $5 \mu \mathrm{M}$ SYTO 9 (Invitrogen, Carlsbad, CA) and 0.5 U HotStarTaq (Qiagen). The cycling and melting conditions were; one cycle of $95^{\circ} \mathrm{C}$ for 15 minutes; 55 cycles of $95^{\circ} \mathrm{C}$ for 10 seconds, $67.5^{\circ} \mathrm{C}$ for 5 seconds with an initial 10 cycles of touchdown from $67.5^{\circ} \mathrm{C}$ to $57.5^{\circ} \mathrm{C}\left(1^{\circ} \mathrm{C} /\right.$ cycle), $72^{\circ} \mathrm{C}$ for 20 seconds; one cycle of $97^{\circ} \mathrm{C}$ for one minute and a melt from $70^{\circ} \mathrm{C}$ to $95^{\circ} \mathrm{C}$ rising $0.2^{\circ} \mathrm{C}$ per second. For LCN-HRM, the conditions were the same except that 60 cycles of amplification were used. The 
cycling conditions for the EGFR exon 19 assay were identical except that the initial annealing temperature was $65^{\circ} \mathrm{C}$. The melting profiles of amplicons were analysed using the Rotor-Gene Software (v1.7).

\section{Preparation of standard dilutions using quantitative real- time PCR (qPCR)}

The amount of amplifiable template for each DNA sample is most accurately estimated by qPCR, particularly when an accurate dilution series is required. For high quality DNA, any amplicon should yield similar results. We used previously reported KRAS primers which generated a 189 bp product [14] and EGFR primers which generated a 250 bp product [14]. PCR conditions were as above. The cycle threshold $(\mathrm{Ct})$ value was determined by setting the threshold at 0.1 in the quantitation analysis of the Rotor-Gene software. Using the qPCR data, a range of cell line DNA dilutions from $20 \%$ to $1 \%$ mutant allele frequency was prepared.

qPCR for copy number estimation prior to limiting dilution When dealing with FFPE specimens, the degree of fragmentation will affect the amount of template molecules that can be amplified. The effective copy number of amplifiable template for each DNA sample is again most accurately estimated by qPCR. In high quality DNA, there is an average of one copy of an autosomal gene per $3 \mathrm{pg}$ of DNA. The effective copy number in the sample is obtained by comparing the $\mathrm{Ct}$ of the sample with the $\mathrm{Ct}$ value of a high quality reference. To correct for the variable amounts of DNA fragmentation, the amplicon used for the estimation needs to be in the same size range as the amplicons being screened for mutations. It is ideal to use the same amplicon that is being screened.

The qPCR data was used for calculation of the dilution factor which gave approximately four copies of template (12 pg) per reaction. To estimate the necessary dilution, the $\mathrm{Ct}$ value of the sample $\left(C t_{s}\right)$ was compared to the $\mathrm{Ct}$ value of reference DNA $\left(C t_{r e f}\right)$ of a known concentration. The comparative quantitation analysis of the Rotor-Gene software was used to calculate the PCR efficiency (E) and the relative amounts of amplifiable template are related the formula $\mathrm{E}^{(\mathrm{Ctref}-\mathrm{Cts})}$. The amounts of template of each test sample were then accordingly diluted.

\section{Sensitivity determination of sequencing and HRM}

Dilutions of the KRAS mutant HCT116 cell line $(20 \%$, $10 \%, 5 \%$ and $1 \%$ ) were used to assess the relative sensitivity of DNA sequencing and HRM. The sensitivity testing was performed with primers and conditions for the 189 bp KRAS product as above. Sequencing reactions for each DNA dilution were performed using the Big Dye Terminator v3.1 (Applied Biosystems, Foster City, CA) and the results were analysed using Sequencher 4.6 (Gene Codes Corporation, Ann Arbor, MI).

\section{Detection of low levels of mutation by LCN-HRM in reconstruction experiments}

The KRAS and EGFR mutant cell lines, HCT116 and NCIH1650, were used to show that LCN-HRM can detect low levels of different types of mutations (missense mutations and deletions respectively) and also to show that the mutations can be characterised by subsequent sequencing of individual LCN-HRM positive reactions.

Each cell line DNA was initially diluted at 5\% mutant allele frequency by mixing with normal peripheral blood DNA based on qPCR data. The 5\% cell line DNA mixtures were then further diluted to an estimate of average four copies in a one microlitre volume. Both cell line DNA dilutions were tested by LCN-HRM in 65 replicates with known positive and negative controls.

Quantitation of low-levels of mutant alleles by LCN-HRM The frequency of a mutant allele may be estimated by analysis of LCN-HRM reactions. The frequency of LCNHRM positive reactions approximates the amount of mutant alleles present in the sample when the mutation frequency is low.

$\mathrm{Fr}=\{$ number of tubes with positive reations $/($ total number of tubes $\times$ average copy number $)\}$ For example, if 25 out of 72 LCN-HRM reactions (which were tested with an average of four copies per reaction) were scored as positive by melting curve analysis, the estimated frequency of the mutant allele would be $8.7 \%\{25 /$ $(72 \times 4)\}$. As the frequency of the mutant allele increases or the average copy number per reaction increases, this formula will become less accurate due to the possibility of two mutant sequences being found in one reaction.

\section{LCN-HRM of FFPE samples}

DNA was previously extracted from four selected NSCLC samples (TX13, TX49, TX86 and TX450) [15]. The first three samples were positive for EGFR mutations by HRM but not sequencing and the last sample was positive for KRAS mutation by HRM but not sequencing. We tested those samples by LCN-HRM to review the discrepancies between HRM and the sequencing results. KRAS exon 2 LCN-HRM conditions were as above. TX13 was tested for mutations in EGFR exon 19 (250 bp product), and TX49 and TX86 were screened for mutations in EGFR exon 21 (212 bp product). EGFR LCN-HRM assays were carried out as previously described for HRM assays [14] except that 65 cycles of amplification were performed. All samples were tested in 64 replicates using an estimated three to four templates per LCN-HRM reaction except TX13 which was tested with less template (estimated 1 template per reaction) due to the limited template available. 
Positive reactions showing aberrant melting profiles were selected and individually sequenced to verify the LCNHRM results. The selected LCN-HRM products were directly column-purified using the PCR-M clean up kit (Viogene, Taipei, Taiwan) and were eluted in a final volume of $30 \mu \mathrm{l}$.

\section{LCN-HRM using DNA polymerases with proofreading activity}

Two different reagent kits with proofreading activity were assessed for their ability to accurately detect mutations: the FastStart High Fidelity PCR System (Roche) and HotStar HiFidelity polymerase (Qiagen). The fidelity was reported to be approximately four-fold (FastStart High Fidelity System) and ten-fold (HotStar HiFidelity) higher than HotStarTaq DNA polymerase (Qiagen). TX84 DNA was tested using LCN-HRM for EGFR exon 21 using the two kits. LCN-HRM was performed on the Rotor-Gene Q for both.

For the FastStart High Fidelity PCR System (Roche), the reaction mixture in a final volume of $20 \mu \mathrm{l}$ contained; $1 \times$ PCR buffer, $2.5 \mathrm{mM} \mathrm{MgCl}_{2}, 200 \mathrm{nM}$ each primer, $200 \mu \mathrm{M}$ dNTPs, $5 \mu \mathrm{M}$ SYTO 9, 1 U FastStart High Fidelity polymerase. The cycling conditions were; one cycle of $95^{\circ} \mathrm{C}$ for 2 minutes; 60 cycles of $95^{\circ} \mathrm{C}$ for 10 seconds, $65^{\circ} \mathrm{C}$ for 10 seconds with an initial 10 cycles of touchdown $\left(1^{\circ} \mathrm{C} /\right.$ cycle), $72^{\circ} \mathrm{C}$ for 30 seconds; one cycle of $97^{\circ} \mathrm{C}$ for one minute and a melt from $70^{\circ} \mathrm{C}$ to $95^{\circ} \mathrm{C}$ rising $0.2^{\circ} \mathrm{C}$ per second.

For HotStar HiFidelity enzyme (Qiagen), the reaction mixture in a final volume of $20 \mu$ l contained; $1 \times$ PCR buffer, $1.5 \mathrm{mM} \mathrm{MgSO}_{4}, 200 \mathrm{nM}$ each primer, $1.5 \mathrm{mM}$ dNTPs, $5 \mu \mathrm{M}$ SYTO 9, 0.5 U HotStar HiFidelity polymerase. The cycling conditions were; one cycle of $95^{\circ} \mathrm{C}$ for 5 minutes; 60 cycles of $95^{\circ} \mathrm{C}$ for 10 seconds, $67.5^{\circ} \mathrm{C}$ for 10 seconds with an initial 10 cycles of touchdown $\left(1^{\circ} \mathrm{C} /\right.$ cycle), $72^{\circ} \mathrm{C}$ for 60 seconds; one cycle of $97^{\circ} \mathrm{C}$ for one minute and a melt from $70^{\circ} \mathrm{C}$ to $95^{\circ} \mathrm{C}$ rising $0.2^{\circ} \mathrm{C}$ per second. All conditions were tested in 64 replicates.

\section{Results \\ The sensitivity of mutation detection by sequencing and HRM}

The relative sensitivity of mutation detection by dideoxynucleotide sequencing and HRM was compared using dilutions of HCT116 DNA (heterozygous for the c.38G>A KRAS mutation) in normal DNA. To ensure the maximum accuracy in the sensitivity determination, qPCR of the KRAS amplicon was used to estimate the effective concentration of each DNA sample. The HCT116 cell line DNA was then serially diluted into normal DNA at ratios of $40 \%, 20 \%, 10 \%$ and $2 \%$ to give mutant allele frequencies of $20 \%, 10 \%, 5 \%$ and $1 \%$.
Dideoxynucleotide sequencing and HRM were performed at each of the mutant allele frequencies (Figure 1). The mutant A allele was still detectable (at a low peak height) when the mutant allele frequency was $20 \%$. However, when the mutant allele was present at $10 \%$, it was only distinguishable from the sequencing background because the site of mutation was known. When the frequency of the mutant was below $10 \%$, the mutation was not detectable by dideoxynucleotide sequencing. Using HRM, the $5 \%$ dilution was readily detectable. The $1 \%$ dilution was not distinguishable from the normal DNA controls.

\section{Detection of low levels of mutation by LCN-HRM}

HCT116 and NCI-H1650 DNA dilutions with a 5\% mutant allele frequency were sequencing negative for KRAS exon 2 missense and EGFR exon 19 deletion mutations respectively (Figure 1, data not shown for EGFR exon 19). The same DNA mixtures were tested by LCNHRM with an estimate of average of three copies of template per reaction. Melting curve analysis of LCN-HRM amplicons led to the identification of positive reactions which were expected to contain mutant alleles. 8/58 LCNHRM reactions of the 5\% HCT116 DNA mixture and 12/ 59 reactions of the 5\% NCI-H1650 DNA mixture showed aberrant melting. Subsequent sequencing of those positive reactions clearly showed the presence of the c.38G $>A$ KRAS mutation and delE746_A750 EGFR mutation respectively (Figure 2 ).

\section{The possible causes of discrepant results between sequencing and HRM}

Four NSCLC samples extracted from FFPE tissues were tested by LCN-HRM to investigate the cause of discrepant results between HRM and sequencing. TX450 was negative by sequencing but positive by HRM for KRAS exon 2 [15]. After LCN-HRM which was performed with estimated averages of four and seven copies per reaction, the melting pattern of each individual reaction was analysed. A total of $18 / 64$ and 30/64 LCN-HRM reactions, displaying heteroduplex melting patterns or a shift of $\mathrm{T}_{\mathrm{m}}$ were scored as positive with four and seven copies respectively. The frequency of mutant alleles was estimated to be $7 \%$ with four copies $\{18$ LCN-HRM positives $/(64 \times 4)\}$ and $6.7 \%$ with seven copies $\{30 \mathrm{LCN}-\mathrm{HRM}$ positive $/(64 \times 7)\}$. The same KRAS mutation, c.34G>T (p.G12C), was repeatedly detected when individual LCN-HRM positive reactions ( 9 from the reactions with four copies and 10 from the reactions with seven copies) were sequenced (Figure 3 ). Even though, the mutant allele was detectable in reactions with both four and seven copies, it was predictably more readily detectable with four copies, resulting in reliable characterisation of mutation by sequencing of multiple LCN-HRM positive reactions. 


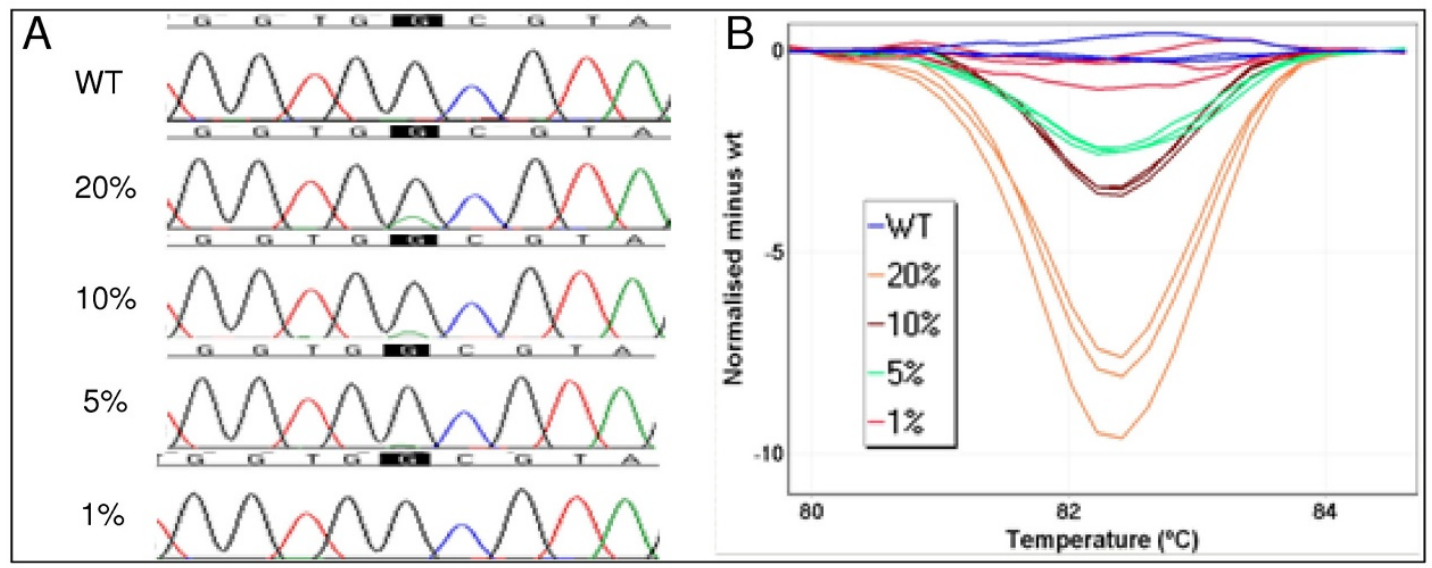

Figure I

Comparison of the mutation detection sensitivity of high resolution melting (HRM) and sequencing. The sensitivity of KRAS HRM and dideoxynucleotide sequencing was tested using four HCTI I 6 DNA dilutions. Based on qPCR data, the HCTI I 6 DNA was mixed with wild-type DNA to dilute the mutant allele to $20 \%, 10 \%, 5 \%$, and I $\%$ of the total alleles. Sequencing was only sensitive to $10-20 \%$ whereas HRM readily detected $5 \%$ mutant sequence. Panel A: Sequencing traces of four HCTI 6 DNA dilutions. The mutant A allele was readily detectable at a $20 \%$ mutant frequency. However, when the mutant allele was present at 10\%, it was barely distinguishable from the sequencing background. When the frequency of the mutant was below $10 \%$, the mutation was not detectable by dideoxynucleotide sequencing. Panel B: Using HRM, the mutation was readily detectable down at $5 \%$ mutation frequency. The $1 \%$ dilution was not distinct from the normal DNA. The melting curves of each dilution are shown in orange (20\%), brown (10\%), green (5\%), red (I\%) and blue (wild-type control).

Non-identical KRAS sequence variants were also detected in five of the other LCN-HRM reactions; c.22G>A, c. $32 \mathrm{C}>\mathrm{A}, \mathrm{c} .38 \mathrm{G}>\mathrm{A}, \mathrm{c} .59 \mathrm{C}>\mathrm{T}$ and c. $100 \mathrm{C}>\mathrm{T}$. These transitional changes have not been previously reported, except those at positions 32 and 38. A transitional $\mathrm{C}>\mathrm{T}$ change, as opposed to a tranversional $\mathrm{C}>\mathrm{A}$, has been reported at c.32 in a few cases whereas $G>A$ change at c.38 (codon 13) has been frequently reported. This illustrates the potential dangers of working from just one sequence in a digital or low copy number situation.

Three other FFPE samples from NSCLC patients were also investigated by LCN-HRM for mutations in EGFR exons 19 (TX13) and 21 (TX49, TX86). After sequencing the LCM-HRM positive products, multiple non-identical sequence variants at different positions were detected in all three samples. Those sequence variants are highly likely to be artefacts. A total of 5 different EGFR sequence variants, four exonic and one intronic, were found in TX13 (Figure 4). All of the variants were single base substitutions with predominantly transitional changes $(4 / 5)$. Among these, two different sequence variations (c.2192G>A and c.2224G>A) were found in one amplicon (reaction 24). Similarly, a total of 12 and 7 sequence variants, again predominantly transitional changes, were identified in TX49 (Table 1) and TX86 respectively (Table 2 ). Interestingly, a c. $2488 \mathrm{G}>\mathrm{A}$ change was found in two independent amplicons of TX49. This mutation has not been previously reported. This is difficult to interpret as it may either represent a low level mutation in a background of sequencing artefacts or a high probability sequencing artefact.

\section{LCN-HRM using DNA polymerases with proofreading activity}

As the LCN-HRM assays were carried out with a Taq DNA polymerase lacking proofreading activity, we investigated whether the PCR artefacts were caused by polymerase error or chemical damage to the FFPE DNA by using two DNA polymerases having different levels of fidelity. We hypothesised that if PCR artefacts were entirely DNA polymerase mediated, the frequency of PCR artefacts would decrease as the polymerase fidelity increased. The fidelity of the polymerases were reported to be approximately four-fold (FastStart High Fidelity System, Roche) and ten-fold (HotStar HiFidelity, Qiagen) higher compared to the Taq polymerase.

One DNA sample (TX86) was tested with all three polymerases. When the Taq polymerase lacking proofreading activity (HotStar Taq) was used, nine out of 58 reactions (15.5\%) were positive by LCN-HRM. A similar LCN-HRM positive rate was detected with the FastStart High Fidelity enzyme. Five out of 32 reactions (15.6\%) were positive. Surprisingly, the highest LCN-HRM positive rate was found with the HotStar HiFidelity enzyme. 


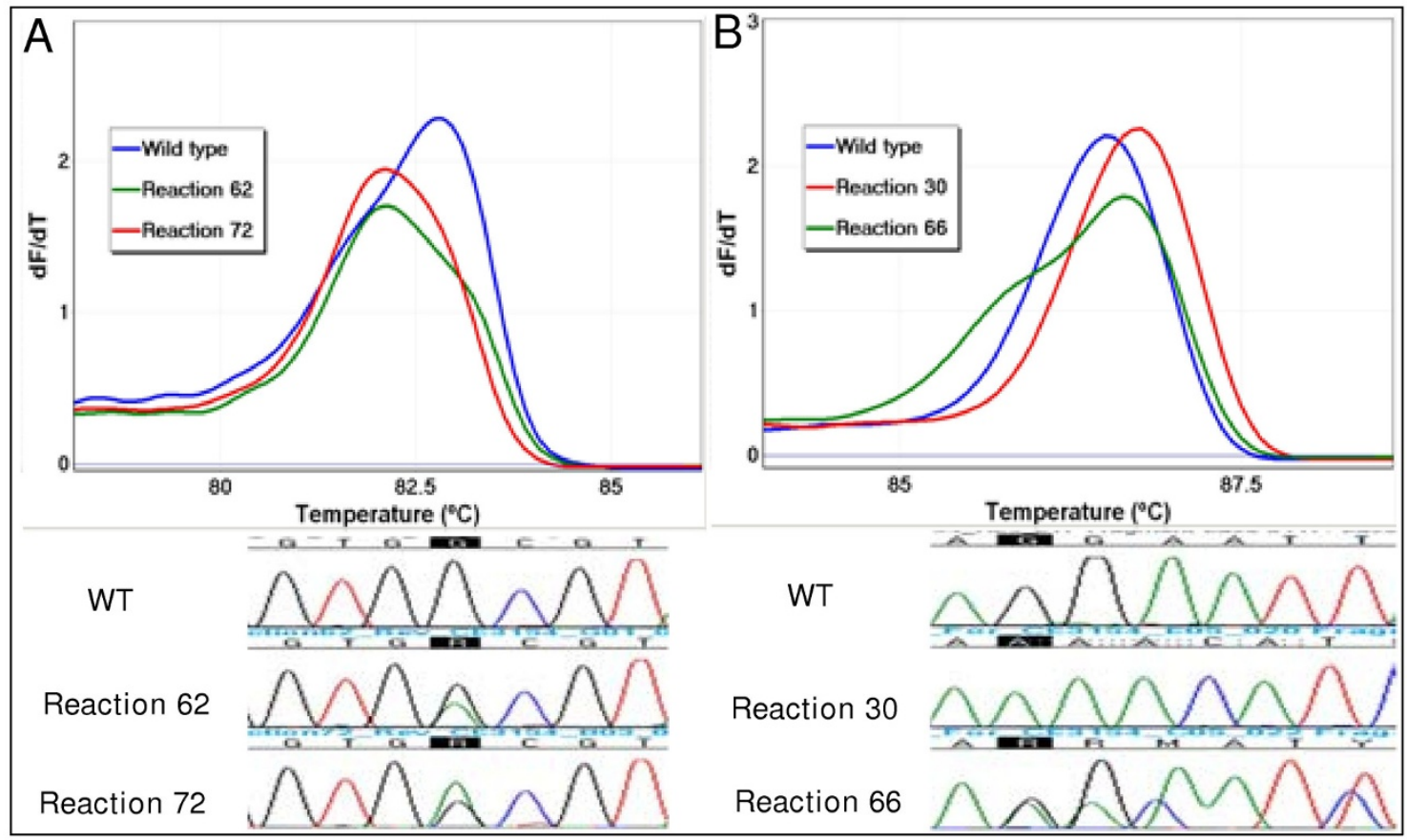

Figure 2

Detection of low levels of mutations by LCN-HRM and characterisation by subsequent sequencing. HCTII 6 and $\mathrm{NCl}-\mathrm{HI} 650$ cell line DNA were mixed with normal DNA to a $5 \%$ mutant allele frequency based on the previous qPCR data. Each of the DNA mixtures were then tested by LCN-HRM in 65 replicates. An estimated average of three copies per reaction were added into the individual reaction. LCN-HRM using the diluted $5 \% \mathrm{HCTI} 16$ and $5 \% \mathrm{NCl}-\mathrm{HI} 650$ was performed for KRAS exon 2 and EGFR exon 19 respectively. LCN-HRM positive reactions, which were detected by melting curve analysis, were directly sequenced. The first derivative melting plots and sequencing traces of two of the representative LCN-HRM positive reactions are shown. (Panel A for 5\% HCTII 6 and Panel B for 5\% NCl-HI650). The identical KRAS mutation to the HCTI I6, c.38G >A, was detected by sequencing of reactions 62 and 72, which displayed aberrant melting pattern compared with wild type. The EGFR delE746_A750 was detected heterozygously in reaction 66 and a homozygously in reaction 30 by sequencing.

Twenty-eight of $53(52.8 \%)$ reactions were positive by LCN-HRM (Table 3).

Numerous non-identical sequence variants were detected in the sequencing of those 42 LCN-HRM positive reactions (Table 2). The sequence variants were likely to be PCR artefacts and the frequency of PCR artefacts was not reduced with DNA polymerases having different levels of proofreading activity, indicating that the artefacts were principally due to damaged template.

\section{Discussion}

Overcoming the limits of detection of sequencing by LCNHRM

Molecular diagnostic testing of clinical tumour samples, in which the tumour cells may comprise a small part of the cellular material and where the quantity of sample for analysis is limited, necessitates the use of highly sensitive methods which are performable with low levels of template. The gold standard method has been sequencing but newer more sensitive methods often give results which cannot be validated by the less sensitive conventional sequencing methodology.

We developed a new screening method, LCN-HRM, for the sensitive detection of sequence variation. LCN-HRM uses limiting dilution of the DNA template for stochastic mutant allele enrichment [20] followed by HRM for rapid screening. The dilutions used are chosen such that mutations if present can be detected well within the analytic sensitivity of both HRM and conventional sequencing. Thus any sequence variant present in aberrant melts can be readily identified as the HRM products may be directly sequenced.

The amount of starting template can affect the efficiency of LCN-HRM due to the masking effect of wild-type allele, when it is present at too high levels. On the contrary, the use of suboptimal amounts of template increases the rate of non-informative reactions giving no amplification. 


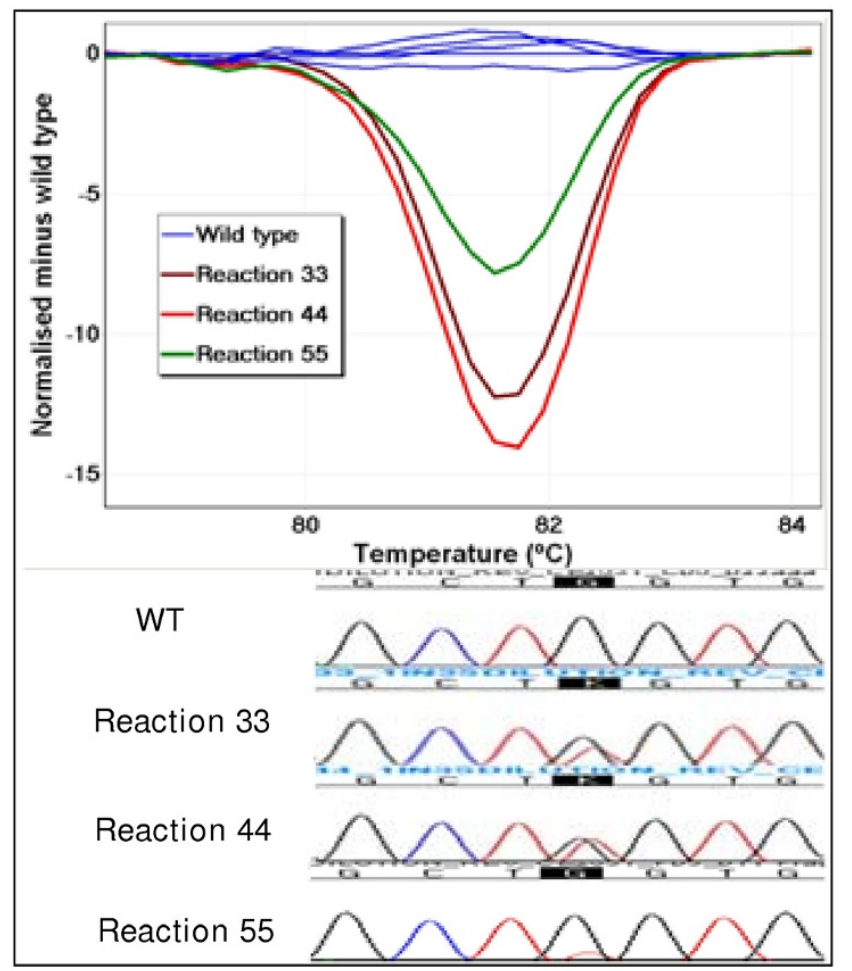

Figure 3

Detection of a KRAS mutations by LCN-HRM in a sequencing negative clinical sample. Testing of a clinical non-small cell lung cancer sample, TX450, for KRAS exon 2 by sequencing gave a negative result whereas the sample was positive by HRM. LCN-HRM was thus performed in 64 replicates using an estimate of average four copies per reaction. The difference graph plot and sequencing traces of three representatives of LCN-HRM positive reactions are shown. A KRAS c.34G $>\mathrm{T}$ was detected in all three reactions by subsequent sequencing.

Table I: Sequence variants detected in a NSCLC FFPE sample, TX49, by LCN-HRM.

\begin{tabular}{|c|c|c|c|c|}
\hline Sample & Position & Base change & Amino acid change & Reported \\
\hline \multirow[t]{13}{*}{ TX49 } & c.2488 & $G>A$ & p.D830N & No \\
\hline & c. 2488 & $G>A$ & p.D830N & No \\
\hline & c.2499 & $G>A$ & p.L833L & No \\
\hline & c. 2502 & $G>A$ & p.V834V & No \\
\hline & c. 2506 & $C>T$ & p.R836C & Yes \\
\hline & c. 2507 & $\mathrm{G}>\mathrm{T}$ & p.R836L & No \\
\hline & c. 2519 & $C>T$ & p.A840V & No \\
\hline & c. 2526 & $C>T$ & p.N842N & No \\
\hline & c. 2577 & $C>T$ & p.A859A & No \\
\hline & c. 2581 & $C>T$ & p.L86IL & No \\
\hline & c. 2593 & $G>A$ & p.E865K & Yes \\
\hline & c. 2603 & $A>G$ & p.E868G & Yes \\
\hline & c. $2625+1$ & $G>A$ & - & No \\
\hline
\end{tabular}

Using Ct values to estimate the effective number of template molecules allows for the ready choice of an optimal dilution to approximately four copies.

\section{LCN-HRM for the detection of low level mutations in clinical samples}

LCN-HRM was used to investigate the possible cause of discordant results between HRM and sequencing. In our previous HRM study of EGFR and KRAS mutations in FFPE clinical samples, we observed that the number of HRM positive samples were higher than sequencing positive samples [15]. In this study, we tested selected samples from that study with LCN-HRM to investigate the apparent discrepant results between sequencing and HRM.

One sample, TX450, was selected for LCN-HRM analysis because although it was sequencing negative for a KRAS exon 2 mutation, HRM showed similar aberrant melting in replicates indicating the presence of a mutation. The sample had an estimated $20 \%$ tumour content at histological review. The detection of the identical KRAS mutation (c.34G>T, p.G12C) in 19 multiple independent LCNHRM replicates proves that the discordant results originated from the different sensitivity of the two methods.

\section{Frequent occurrence of artefacts in FFPE DNA samples}

Another possible cause of discrepancy between HRM and sequencing is due to PCR artefacts as various non-identical sequence variations were identified in the other three FFPE samples tested. Artificial sequence changes are reportedly mediated by DNA polymerase error and/or damaged DNA templates [22,23]. A variety of DNA polymerase-mediated sequence changes can occur during PCR amplification including single base substitutions, deletions and insertions. Among these changes, single base substitutions result from misincorporation of incorrect dNTPs and are the most common type of artefactual change. DNA damage induced during tissue fixation and 
Table 2: The sequence variants detected in TX86 by LCN-HRM using three different DNA polymerases.

\begin{tabular}{|c|c|c|c|c|}
\hline Polymerase & Position & Base change & Amino acid change & Reported \\
\hline \multirow{7}{*}{$\begin{array}{l}\text { HotStarTaq } \\
\text { (Qiagen) }\end{array}$} & c. 2515 & $\mathrm{G}>\mathrm{T}$ & p.A839S & No \\
\hline & c. 2519 & $\mathrm{C}>\mathrm{T}$ & p.A840V & No \\
\hline & c. 2527 & $G>A$ & p.V842I & Yes \\
\hline & c. 2532 & $G>A$ & p.L844L & No \\
\hline & c. 2583 & $G>A$ & P.L86IL & No \\
\hline & c. 2588 & $G>A$ & p.G863D & Yes \\
\hline & c. 2592 & $G>A$ & p.A864A & No \\
\hline \multirow{5}{*}{$\begin{array}{l}\text { FastStart High Fidelity } \\
\text { (Roche) }\end{array}$} & c. 2602 & $G>A$ & p.E868K & No \\
\hline & c. 2494 & $\mathrm{C}>\mathrm{T}$ & p.R832C & No \\
\hline & c. 2512 & $\mathrm{C}>\mathrm{T}$ & p.L838L & No \\
\hline & c. 2570 & $G>T$ & p.G857V & No \\
\hline & c. 2576 & $\mathrm{C}>\mathrm{T}$ & p.A859V & No \\
\hline \multirow{17}{*}{$\begin{array}{l}\text { HotStar HiFidelity } \\
\text { (Qiagen) }\end{array}$} & c. 2478 & $C>A$ & p.N826K & No \\
\hline & c. 2484 & $G>T$ & p.L828F & No \\
\hline & c. 2488 & $G>T$ & p.D830Y & No \\
\hline & c. 2492 & $G>A$ & p.R83IH & Yes \\
\hline & c. 2494 & $\mathrm{C}>\mathrm{T}$ & p.R832C & No \\
\hline & c. 2508 & $C>A$ & p.R836R & SNP \\
\hline & c.2508_2509 & CG $>$ TA & p.R836R, p.D837N & No \\
\hline & c. 2509 & $\mathrm{G}>\mathrm{T}$ & p.D837Y & No \\
\hline & c. 2515 & $G>A$ & p.A839T & Yes \\
\hline & c. 2517 & $A>G$ & p.A839A & No \\
\hline & c. 2522 & $G>T$ & p.R84IM & No \\
\hline & c. 2530 & $C>A$ & p.L844M & No \\
\hline & c. 2543 & $C>A$ & p.P848Q & No \\
\hline & c. 2581 & $C>A$ & P.L86IM & No \\
\hline & c. 2591 & $C>T$ & p.A864V & No \\
\hline & c. 2607 & $C>A$ & p.Y869X & No \\
\hline & c. 2622 & $C>A$ & p.G874G & No \\
\hline
\end{tabular}

storage process is another well-documented source of PCR artefacts [23]. These PCR artefacts are randomly distributed and thus are masked by the abundant normal sequences if high amounts of starting template are used. In HRM analysis, a higher frequency of aberrant melting is observed with FFPE DNA compared to high quality DNA sample as the individual random PCR artefacts are cumulatively reflected on the resulting melting curve (results not shown).

\section{Determining the origin of PCR artefacts}

To understand whether the fidelity of DNA polymerase is associated with the generation of PCR artefacts, we used three DNA polymerase kits possessing different levels of proofreading activity. The frequency of LCN-HRM positive reactions was compared in the EGFR exon 21 assay using a FFPE sample, TX86, which had previously shown aberrant HRM melting profiles. The rate of PCR artefacts (which were confirmed by sequencing) was not reduced as the fidelity of DNA polymerase was increased (Table 2).
Thus, the damaged DNA template is likely to be the principal cause of PCR artefacts. In support of this, when a peripheral blood DNA was tested by LCN-HRM using the same conditions for KRAS exon 2, no amplicons showing aberrant melting were detected (data not shown).

It is interesting that a higher LCN-HRM positive rate is seen in LCN-HRM performed with the DNA polymerase kit having the highest proofreading activity. This may be explained by considering that mutation-prone translesional extension at damaged DNA sites occurred more frequently, resulting in subsequent generation of more artefactual changes. The occurrence of translesional synthesis at abasic sites has been previously reported with a Taq polymerase with proofreading activity [24].

It is important to distinguish PCR artefacts from true mutations in the results obtained from FFPE material by LCN-HRM. The detection of an identical nucleotide change at one position in over two or more independent 


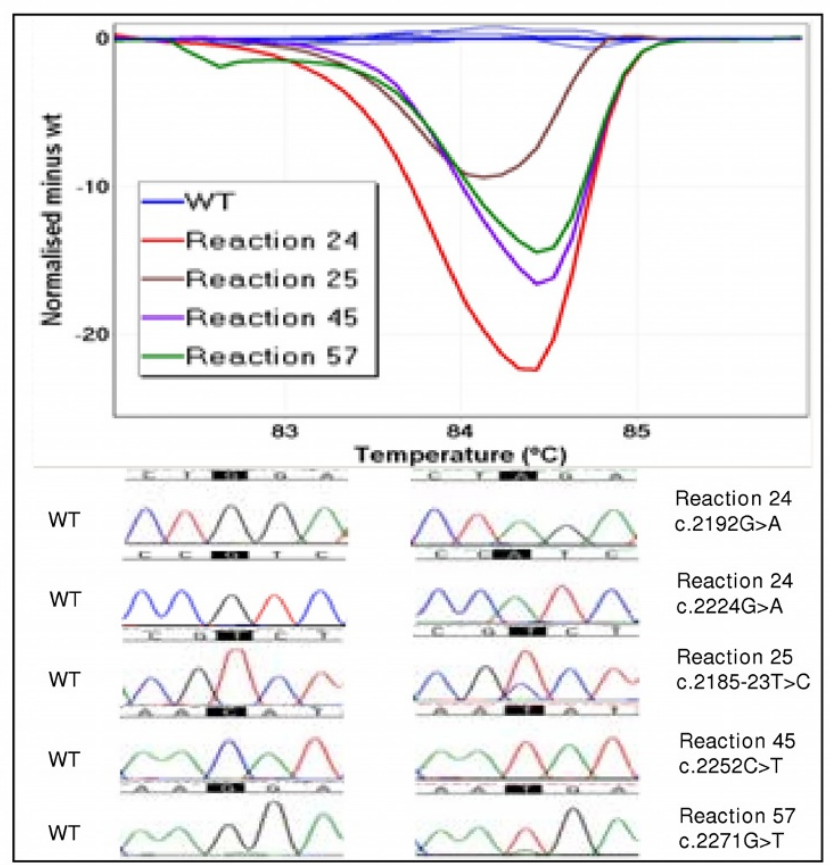

Figure 4

PCR artefacts detected in in a clinical FFPE sample (TXI3). A total of 8 out of 3 I LCN-HRM reactions were positive by melting curve analysis. Five non-identical sequence variants were detected from 4 of the 8 LCN-HRM positive reactions sequenced. In reaction 24 , two transitional G>A changes were detected at positions c.2192 and c.2224. Two other exonic (c.2252C>T and c.227IG >T) and one intronic (c.2185-23T>C) variants were also detected in reactions 45,57 and 25 respectively.

PCR products is supportive of a true mutation whereas nonidentical changes randomly distributed in the template sequence should be considered as PCR artefacts. In addition, weight should be given to those mutations that are observed at well known (canonical) sites of mutation over those mutations that occur at non-canonical sites. Using these criteria, the identical KRAS mutation (c.34G>T) detected in multiple independent LCN-HRM products amplified from the TX450 can be considered as a true mutation. However, any variations that fail to be confirmed would be more appropriately interpreted as
PCR artefacts as seen in TX13, TX49 and TX86 (Tables 1 and 2, Figure 4).

Fixation of tissue specimens in neutral buffered formalin $(10 \%)$ is a widely used preservation method as it helps to maintain morphological features [23]. The adverse effect of formalin on DNA quality results in fragmentation of DNA into small sizes [25]. In addition, the incidence of PCR artefacts has increased the risk of misinterpretation of results obtained from formalin-fixed tissues [26,27]. Furthermore, studies of chemical reactions between formaldehyde and DNA have demonstrated several chemical interactions; formation of hydroxymethyl groups and methylene bridges, generation of apurinic and apyrimidinic sites, and hydrolysis of phosphodiester bonds $[28,29]$. As a result, more frequent DNA polymerase errors have been detected on FFPE material than fresh frozen tissues $[26,30]$.

Although the exact mechanism for the artefacts has not been elucidated, several explanations are possible. Firstly, adenosine residues tend to be incorporated complementary to damaged or cross-linked cytosine nucleotides, due to the so-called "A-rule", generating G to A (or C to T) mutations [26,31]. In this study, nearly all the base changes were $\mathrm{G}$ to A or $\mathrm{C}$ to $\mathrm{T}$ mutations (Tables 1 and 2). In addition, when Taq polymerase encounters damaged templates, it has a propensity to stop nucleotide incorporation and to insert an non-complementary adenosine residue into the strand being synthesised. The formalininduced DNA damage promotes jumping of the extending primer to another template where extension of the primer continues [32].

As FFPE tissue is frequently used for genetic analysis, the results should thus always be cautiously interpreted. Tsao et al. reported an incidence of 45 EGFR mutations in 177 NSCLC patients, comprising 13 deletions and 32 point mutations [33]. However, due to the high frequency (53 percent) of novel variants with predominantly transition changes ( 92 percent) in this study as well as the lack of adequate confirmation, those changes were suggested to be PCR artefacts [34,35], which is consistent with our observations.

Table 3: The frequency of LCN-HRM positives measured with different DNA polymerases in a NSCLC FFPE sample, TX86.

\begin{tabular}{cccc}
\hline LCN-HRM & $\begin{array}{c}\text { HotStarTaq } \\
\text { (Qiagen) }\end{array}$ & $\begin{array}{c}\text { FastStart High Fidelity } \\
\text { System (Roche) }\end{array}$ & $\begin{array}{c}\text { HotStar HiFidelity } \\
\text { Polymerase (Qiagen) }\end{array}$ \\
\hline Proofreading* & 0 & 4 -fold & 10 -fold \\
Positive & $9(15.5 \%)$ & $5(15.6 \%)$ & $28(52.8 \%)$ \\
Negative & $49(84.5 \%)$ & $27(84.4 \%)$ & $25(47.2 \%)$ \\
Total & $58(100 \%)$ & $32(100 \%)$ & $53(100 \%)$ \\
\hline
\end{tabular}

\footnotetext{
* Proofreading activity was relatively compared to that of a Taq DNA polymerase. HRM: high resolution melting.
} 
Recently, a large number of non-canonical EGFR mutations were reported in both the stromal and epithelial tissue in breast cancer [36]. The same group also reported the occurrence of TP53 mutations in both the stromal and epithelial tissue in breast cancer [37]. However, in an independent study, no TP53 mutations were detected in stroma of 17 breast cancer or breast cancer-associated fibroblast cultures [38]. The vast majority of the "mutations" reported are thus likely to be the same type of PCR artefacts that we have observed in several of our samples especially as the variants occurred at non-canonical sites and were not adequately confirmed by sequencing of independent PCR products. Consistent with this, the predominant change seen in the samples was a transitional $\mathrm{G}>\mathrm{A}(\mathrm{C}>\mathrm{T})$ change $[39,40]$.

In many cases, mutation analysis of FFPE samples in routine diagnostic situations involves low copy numbers being amplified due to the combination of limited amounts of template and degradation of DNA. Thus, a low copy number may arise inadvertently. Such cases are usually marked by late amplification and often by heterogeneity of melting patterns between samples. Interpretation is similar to that above. Sequencing is necessary to interpret the results and the presence of a mutational change must be confirmed using sequencing of independent reactions. In some cases, further dilution may be warranted to optimise the copy number being analysed.

In conclusion, we have developed a new screening method, LCN-HRM, for detection of low levels of sequence variation. Analysis of multiple replicates of low copy numbers of template allows both the detection of templates with variant sequence (mutations) and enables sequencing to identify the precise changes involved.

The previously reported discrepant results between HRM and sequencing are often due to low level mutant alleles but artefacts due to amplification of low copy numbers or to damaged DNA from FFPE tissues must also be considered. The interpretation of LCN-HRM results should thus be based on the reproducibility and position of detected sequence changes.

\section{Competing interests}

The authors declare that they have no competing interests.

\section{Authors' contributions}

HD participated in the study design, carried out the molecular genetic studies and co-wrote the manuscript. $\mathrm{AD}$ conceived the study, participated in the study design and co-wrote the manuscript. Both authors read and approved the final manuscript.

\section{Acknowledgements}

We thank Carleen Cullinane for the HCTII 6 cell line DNA. We also thank Chelsee Hewitt for critical reading of the final MS. This study was supported in part by the National Health and Medical Research Council of Australia. HD is the recipient of a postgraduate scholarship from the National Health and Medical Research Council of Australia. We thank Stephen Fox, David Westerman and John Zalcberg for their continued support.

\section{References}

I. Sharma SV, Bell DW, Settleman J, Haber DA: Epidermal growth factor receptor mutations in lung cancer. Nat Rev Cancer 2007, 7:169-18I.

2. Ludwig JA, Weinstein JN: Biomarkers in cancer staging, prognosis and treatment selection. Nat Rev Cancer 2005, 5:845-856.

3. Taniguchi K, Okami J, Kodama K, Higashiyama M, Kato K: Intratumor heterogeneity of epidermal growth factor receptor mutations in lung cancer and its correlation to the response to gefitinib. Cancer Sci 2008, 99:929-935.

4. Kobelt DJ, Hees SM, Hildebrandt RD, Wnendt S: Validation of a Method for Automated Nucleotide Sequence Analysis and Estimation of the Limits of Detection of Variant Sequences in a Heterogenic DNA Sample. Analytical Letters 1998, $3 I(1): 4 I-54$.

5. Marchetti A, Martella C, Felicioni L, Barassi F, Salvatore S, Chella A, Camplese PP, larussi T, Mucilli F, Mezzetti A, et al.: EGFR mutations in non-small-cell lung cancer: analysis of a large series of cases and development of a rapid and sensitive method for diagnostic screening with potential implications on pharmacologic treatment. J Clin Oncol 2005, 23:857-865.

6. Endo K, Konishi A, Sasaki H, Takada M, Tanaka H, Okumura M, Kawahara M, Sugiura H, Kuwabara $Y$, Fukai I, et al.: Epidermal growth factor receptor gene mutation in non-small cell lung cancer using highly sensitive and fast TaqMan PCR assay. Lung Cancer 2005, 50:375-384.

7. Kimura H, Kasahara K, Kawaishi M, Kunitoh H, Tamura T, Holloway B, Nishio K: Detection of epidermal growth factor receptor mutations in serum as a predictor of the response to gefitinib in patients with non-small-cell lung cancer. Clin Cancer Res 2006, I 2:39|5-392I.

8. Janne PA, Borras AM, Kuang Y, Rogers AM, Joshi VA, Liyanage H, Lindeman N, Lee JC, Halmos B, Maher EA, et al.: A rapid and sensitive enzymatic method for epidermal growth factor receptor mutation screening. Clin Cancer Res 2006, 12:75I-758.

9. Ogino S, Kawasaki T, Brahmandam M, Yan L, Cantor M, Namgyal C, Mino-Kenudson M, Lauwers GY, Loda M, Fuchs CS: Sensitive sequencing method for KRAS mutation detection by Pyrosequencing. J Mol Diagn 2005, 7:413-42I.

10. Thomas RK, Nickerson E, Simons JF, Janne PA, Tengs T, Yuza Y, Garraway LA, LaFramboise T, Lee JC, Shah K, et al:: Sensitive mutation detection in heterogeneous cancer specimens by massively parallel picoliter reactor sequencing. Nat Med 2006, I 2:852-855

II. Nomura M, Shigematsu H, Li L, Suzuki M, Takahashi T, Estess P, Siegelman M, Feng Z, Kato H, Marchetti A, et al.: Polymorphisms, mutations, and amplification of the EGFR gene in non-small cell lung cancers. PLoS Med 2007, 4:el 25.

12. Li J, Wang L, Mamon H, Kulke MH, Berbeco R, Makrigiorgos GM: Replacing PCR with COLD-PCR enriches variant DNA sequences and redefines the sensitivity of genetic testing. Nat Med 2008, 14:579-584.

13. Asano H, Toyooka S, Tokumo M, Ichimura K, Aoe K, Ito S, Tsukuda $\mathrm{K}$, Ouchida M, Aoe M, Katayama H, et al: Detection of EGFR gene mutation in lung cancer by mutant-enriched polymerase chain reaction assay. Clin Cancer Res 2006, 12:43-48.

14. Krypuy M, Newnham GM, Thomas DM, Conron M, Dobrovic A: High resolution melting analysis for the rapid and sensitive detection of mutations in clinical samples: KRAS codon 12 and 13 mutations in non-small cell lung cancer. BMC Cancer 2006, 6:295.

15. Do H, Krypuy M, Mitchell PL, Fox SB, Dobrovic A: High resolution melting analysis for rapid and sensitive EGFR and KRAS mutation detection in formalin fixed paraffin embedded biopsies. BMC Cancer 2008, 8:142. 
16. Erali M, Voelkerding KV, Wittwer CT: High resolution melting applications for clinical laboratory medicine. Exp Mol Pathol 2008, 85:50-58.

17. Wojdacz TK, Dobrovic A: Methylation-sensitive high resolution melting (MS-HRM): a new approach for sensitive and highthroughput assessment of methylation. Nucleic Acids Res 2007, 35:e4l.

18. Kristensen LS, Mikeska T, Krypuy M, Dobrovic A: Sensitive Melting Analysis after Real Time- Methylation Specific PCR (SMART-MSP): high-throughput and probe-free quantitative DNA methylation detection. Nucleic Acids Res 2008, 36:e42.

19. Nomoto K, Tsuta K, Takano T, Fukui T, Fukui T, Yokozawa K, Sakamoto H, Yoshida T, Maeshima AM, Shibata T, et al.: Detection of EGFR mutations in archived cytologic specimens of nonsmall cell lung cancer using high-resolution melting analysis. Am J Clin Pathol 2006, I 26:608-6I5.

20. Sykes PJ, Neoh SH, Brisco MJ, Hughes E, Condon J, Morley AA: Quantitation of targets for PCR by use of limiting dilution. Biotechniques 1992, 13:444-449.

21. Simmonds P, Balfe P, Peutherer JF, Ludlam CA, Bishop JO, Brown AJ: Human immunodeficiency virus-infected individuals contain provirus in small numbers of peripheral mononuclear cells and at low copy numbers. J Virol 1990, 64:864-872.

22. Eckert KA, Kunkel TA: DNA polymerase fidelity and the polymerase chain reaction. PCR Methods Appl 1991, 1:17-24.

23. Srinivasan $M$, Sedmak $D$, Jewell $S$ : Effect of fixatives and tissue processing on the content and integrity of nucleic acids. Am J Pathol 2002, 161:1961-1971.

24. Kobayashi A, Kitaoka M, Hayashi K: Novel PCR-mediated mutagenesis employing DNA containing a natural abasic site as a template and translesional Taq DNA polymerase. J Biotechnol 2005, I 1 6:227-232.

25. Greer CE, Lund JK, Manos MM: PCR amplification from paraffinembedded tissues: recommendations on fixatives for longterm storage and prospective studies. PCR Methods Appl I99I, I:46-50.

26. Williams C, Ponten F, Moberg C, Soderkvist P, Uhlen M, Ponten J, Sitbon $G$, Lundeberg J: A high frequency of sequence alterations is due to formalin fixation of archival specimens. Am J Pathol 1999, I55:|467-|47|.

27. Akbari M, Hansen MD, Halgunset J, Skorpen F, Krokan HE: Low copy number DNA template can render polymerase chain reaction error prone in a sequence-dependent manner. $J \mathrm{Mol}$ Diagn 2005, 7:36-39.

28. Douglas MP, Rogers SO: DNA damage caused by common cytological fixatives. Mutat Res 1998, 40 I:77-88.

29. McGhee JD, von Hippel PH: Formaldehyde as a probe of DNA structure. 3. Equilibrium denaturation of DNA and synthetic polynucleotides. Biochemistry 1977, 16:3267-3276.

30. Quach N, Goodman MF, Shibata D: In vitro mutation artifacts after formalin fixation and error prone translesion synthesis during PCR. BMC Clin Pathol 2004, 4:I.

31. Shibutani S, Takeshita M, Grollman AP: Translesional synthesis on DNA templates containing a single abasic site. A mechanistic study of the "A rule". J Biol Chem 1997, 272:13916-13922.

32. Paabo S, Irwin DM, Wilson AC: DNA damage promotes jumping between templates during enzymatic amplification. J Biol Chem 1990, 265:47|8-472I.

33. Tsao MS, Sakurada A, Cutz JC, Zhu CQ, Kamel-Reid S, Squire J, Lorimer I, Zhang T, Liu N, Daneshmand M, et al.: Erlotinib in lung cancer - molecular and clinical predictors of outcome. $\mathrm{N} \mathrm{Engl}$ $J$ Med 2005, 353:133-144.

34. Pao W, Ladanyi M, Miller VA: Erlotinib in lung cancer. $N$ EnglJ Med 2005, 353: 1739-174I. author reply 1739-174|

35. Marchetti A, Felicioni L, Buttitta F: Assessing EGFR mutations. $N$ Engl J Med 2006, 354:526-528. author reply 526-528

36. Weber F, Fukino K, Sawada T, Williams N, Sweet K, Brena RM, Plass C, Caldes T, Mutter GL, Villalona-Calero MA, Eng C: Variability in organ-specific EGFR mutational spectra in tumour epithelium and stroma may be the biological basis for differential responses to tyrosine kinase inhibitors. Br J Cancer 2005, 92:1922-1926.

37. Patocs A, Zhang L, Xu Y, Weber F, Caldes T, Mutter GL, Platzer P, Eng C: Breast-cancer stromal cells with TP53 mutations and nodal metastases. N Engl J Med 2007, 357:2543-255I.
38. Campbell IG, Qiu W, Polyak K, Haviv I: Breast-cancer stromal cells with TP53 mutations. N Engl J Med 2008, 358:1634-1635. author reply 1636

39. Zander CS, Soussi T: Breast-cancer stromal cells with TP53 mutations. N Engl J Med 2008, 358: I 635. author reply 1636

40. Zalcman G, Bergot E, Hainaut P: Breast-cancer stromal cells with TP53 mutations. N Engl J Med 2008, 358: I635-1636. author reply 1636
Publish with Bio Med Central and every scientist can read your work free of charge

"BioMed Central will be the most significant development for disseminating the results of biomedical research in our lifetime."

Sir Paul Nurse, Cancer Research UK

Your research papers will be:

- available free of charge to the entire biomedical community

- peer reviewed and published immediately upon acceptance

- cited in PubMed and archived on PubMed Central

- yours - you keep the copyright
BiolMedcentral 